\title{
Understanding of hydrothermal alteration process from both experiments and geological facts
}

YUANFENG CAI ${ }^{1,2}$, XI ZHAO $^{2}$, HE ZHANG $^{2}$, YANG ZHANG
${ }^{2}$, XIAOKE ZHANG ${ }^{3}$, CHUNXIAO FAN $^{2}$, YUGUAN PAN

${ }^{1}$ State Key laboratory of Mineral Deposit Research, School of Earth and Engineering, Nanjing University, Nanjing 210023, China; caiyf@nju.edu.cn

${ }^{2}$ School of Earth and Engineering, Nanjing University, Nanjing 210023, China;

${ }^{3}$ Department of Bio-medicine, Microspectrum Technology Co., Ltd. Shanghai, China.

Hydrothermal alteration occurs ubiquitously though every spherer of the earth, from core to hydrosphere. It is apt to be detected in active volcanos to which it connects the magama reservior. It impells elements circular to adapt in different physical-chemical conditions through water-rock reactions either in upwelling of magama or subduction of slabs of ocean crusts. Thus, different scales of alteration were usually mentioned in studying of ore deposits, but the role of hydrothermal alteration was neglected in varying degrees.

In this work we carried out two different sets of experiment to simulate mineral phase transformation occuring in both sulfides and clay minerals according to the geological facts. The transformation among sulfides is an analog of ore minerals forming process. The universal transformation among clay minerals might be considered as the analogs of argillary alterations in ore deposits. The assemblages of copper sulfides covers completely $\mathrm{Cu}-\mathrm{S}$ sereies minerals and are present in Zijinshan copper-gold deposit in Fujian China, as well as the ones in Yongping, Jiangxi China. The reported copper sulfides are composed by chalcocite, digenite, anilite, covellite, chalcopyrite etc. excluding bornite. The assemblage differs to the porphyry copper deposits in which the few copper-iron sulfides was reported, such as bornite and chalcopyrite. Copper accumulated continually during entile evolution of magma and tended to form industrial scale of ore deposit since partitioning into non-sulfide minerals is negligible (Lee et al., 2012). The present or absent of iron is a key fact which represents a vitally different of redox of oreforming conditions, to tell the fluid evolving histroy and hydrothermal process. The experiments will explore the ironleaching process.

Acknowledgements: This study was supported by the NSFC Project (41672037 and 41272055) and the National Key Program of China (41830426).

Lee, C.T.A. et al., 2012. Copper Systematics in Arc Magmas and Implications for Crust-Mantle Differentiation. Science, 336(6077): 64-68. 